\title{
PARA UMA TEORIA \\ DO EXEMPLO \\ LEXICOGRÁFICO: \\ FORMAS E FUNÇÕES DA \\ EXEMPLIFICAÇÃO EM \\ DICIONÁRIOS \\ SEMASIOLÓGICOS
}

\section{HACIA UNA TEORÍA DEL EJEMPLO LEXICOGRÁFICO: FORMAS Y FUNCIONES DE LA EJEMPLIFICACIÓN EN DICCIONARIOS SEMASIOLÓGICOS}

TOWARDS A THEORY OF THE LEXICOGRAPHIC EXAMPLE: FORMS AND FUNCTIONS OF EXEMPLIFICATION IN SEMASIOLOGICAL DICTIONARIES

Virginia Sita Farias*

Universidade Federal do Rio de Janeiro

RESUMO: A exemplificação nos dicionários de língua é um tópico de suma importância no âmbito (meta)lexicográfico. Não obstante, ainda não existe um modelo teórico que sirva como base para a elaboração e apresentação de exemplos funcionais em dicionários semasiológicos. O objetivo deste trabalho é propor os fundamentos de uma teoria do exemplo lexicográfico. Para tanto, em primeiro lugar, discutiremos a relação entre a forma do exemplo e suas respectivas funções, e, em segundo lugar, proporemos critérios que permitam converter o exemplo em um fato funcional na microestrutura de obras lexicográficas. PALAVRAS-CHAVE: Exemplo lexicográfico. Informação funcional. Dicionários semasiológicos. (Meta)lexicografia.

RESUMEN: La ejemplificación en los diccionarios de lengua es un tema sumamente importante en el ámbito (meta)lexicográfico. Sin embargo, aún no existe un modelo teórico que sirva de base y soporte para la elaboración y presentación de ejemplos funcionales en diccionarios semasiológicos. El objetivo de este estudio es proponer los fundamentos de una teoría del ejemplo lexicográfico. Para ello, en primer lugar, discutiremos la relación entre la forma del ejemplo y sus respectivas funciones, y, en segundo lugar, propondremos criterios que permitan convertir el ejemplo en un hecho funcional en la microestructura de obras lexicográficas.

PALABRAS CLAVE: Ejemplo lexicográfico. Información funcional. Diccionarios semasiológicos. (Meta)lexicografía.

\footnotetext{
* Professora adjunta de Espanhol na UFRJ desde 2014. Doutora em Lexicografia e Terminologia pelo PPG-Letras da UFRGS (2014) e pós-doutora em Linguística Românica pela Universidade de Paderborn/Alemanha (2018-2019) com bolsa da Fundação Alexandervon Humboldt. E-mail:virginiafarias@hotmail.com.
} 
ABSTRACT: The exemplification in linguistic dictionaries is a topic of major importance in (meta)lexicography. However, there is not yet a theoretical model that supports the presentation of functional examples in semasiological dictionaries. The aim of this paper is to propose the basic principles of a theory of the lexicographic example. To this purpose, firstly, we discuss the relationship between the form of the example and its respective functions, and, secondly, we propose criteria to make the example into a functional information in the microstructure of lexicographic works.

KEYWORDS: Lexicographic example. Functional information. Semasiological dictionaries. (Meta)lexicography.

\section{INTRODUÇÃO}

Existe, no âmbito (meta)lexicográfico, um consenso a respeito da importância do exemplo no cumprimento de diversas funções no interior da microestrutura de dicionários de língua, tais como complementar a definição, apresentar contextos sintáticos, introduzir informações culturais ou atestar a ocorrência de uma palavra ou acepção. A relevância do tema é corroborada pelo número considerável de estudos que retomam o problema da exemplificação nos dicionários de língua (cf., por exemplo, MARTIN, 1989; HARRAS, 1989; MINAEVA, 1992; TOOPE, 1996; HUMBLÉ, 1996; 1998; 2001; GARRIGA ESCRIBANO, 2001; 2003; STEIN, 2002; FOURMENT-BERNI CANANI, 2002; HEINZ, 2002; SIMPSON, 2003; BARGALLÓ ESCRIVÁ, 2008; HILES, 2011; ROBLES I SABATER, 2011; DIDAKOWSKI; LEMNITZER; GEYKEN, 2012; POTGIETER, 2012; JESENŠEK, 2013; FRANKENBERG-GARCÍA, 2015; LIU, 2017; KOSEM, 2017; OSSELTON, 2018; KOSEM et al., 2019; GANTAR et al., 2019; LETTNER, 2020), sem contar o destaque que se costuma conferir ao tema nos manuais de lexicografia (cf., por exemplo, REYDEBOVE, 1971; DUBOIS, 1971; ZGUSTA, 1971; MERZAGORA, 1987; LANDAU, 2001; HERBST; KLOTZ, 2003; WELKER, 2004; SVENSÉN, 2009; KLOTZ; HERBST, 2016). Não obstante, a maioria dos estudos que abordam a questão da exemplificação em dicionários de língua preocupam-se preponderantemente com o estabelecimento de tipologias baseadas quase sempre na distinção entre exemplo e abonação ${ }^{1}$, ou ainda entre as funções de recepção e produção linguística, sem que - pelo menos até o momento - haja sido desenvolvida uma metodologia ${ }^{2}$ que permita garantir a funcionalidade ${ }^{3}$ do exemplo lexicográfico.

O presente artigo é uma sequência das discussões introdutórias realizadas em Farias (2008; 2013, p. 335-348). Nas referidas ocasiões, versava-se sobre a funcionalidade do exemplo, relacionando-o com os demais segmentos microestruturais, e discutiamse os conceitos de "exemplo para compreensão" e "exemplo para produção". Visando ao aprofundamento das questões tratadas nos trabalhos anteriores, o objetivo aqui traçado é relacionar ambos os conceitos - "exemplo para compreensão" e "exemplo para produção" - às distintas formas de exemplificação, a fim de apresentar o que poderiam vir a constituir os fundamentos de uma "teoria do exemplo lexicográfico", no âmbito da qual seja possível determinar a funcionalidade da exemplificação em dicionários semasiológicos ${ }^{4}$ - mais especificamente, em dicionários gerais de língua (com ênfase nos dicionários de português).

\footnotetext{
${ }^{1}$ Sobre a distinção entre exemplo e abonação, cf. seção 2.2.1.1.

${ }^{2}$ Deve-se destacar que há autores, entre os mencionados anteriormente, que buscam propor critérios para aferir a qualidade dos exemplos em obras lexicográficas (por exemplo, ROBLES; SABATER, 2011; KOSEM, 2017; KOSEM et al., 2019), bem como outros que vão inclusive um pouco além, demonstrando uma clara preocupação com a elaboração de uma teoria do exemplo lexicográfico (por exemplo, HARRAS, 1989; LETTNER, 2020; esta última está efetivamente preocupada com a inserção do exemplo no âmbito de um modelo lexicográfico integral, porém limita seu escopo à questão da exemplificação nos dicionários monolíngues e bilíngues para aprendizes de alemão como língua estrangeira). Falta, portanto, relacionar os critérios que definiriam um "bom exemplo" e os que permitiriam determinar seu uso adequado na microestrutura dos dicionários, possibilitando, dessa forma, desenhar o que poderia ser chamada de "teoria integral do exemplo lexicográfico".

${ }^{3}$ Sobre o conceito de funcionalidade da informação, cf. seção 2.

${ }^{4}$ Os dicionários semasiológicos têm como principal característica apresentar paráfrases definidoras (por exemplo, dicionários gerais, dicionários escolares, learner's dictionaries); contrapondo-se a esses, os dicionários onomasiológicos caracterizam-se pelo estabelecimento de relações conceituais entre as palavras (por exemplo, thesauri, dicionários de sinônimos/antônimos, dicionários pela imagem) (cf. Hartmann; James, 2001, s.v. semasiological dictionary; s.v. onomasiological dictionary).
} 


\section{FUNDAMENTOS PARA UMA TEORIA DO EXEMPLO LEXICOGRÁFICO}

Uma teoria do exemplo lexicográfico deve desenvolver-se no âmbito de uma "teoria geral dos mecanismos explanatórios" e, mais amplamente, de uma "teoria (meta)lexicográfica integral".

No âmbito de uma "teoria geral dos mecanismos explanatórios" (cf. FARIAS, 2013), poder-se-ia, idealmente, prever o grau de opacidade das paráfrases definidoras, e consequentemente, determinar a necessidade de emprego de mecanismos explanatórios complementares - entre os quais se encontram, logicamente, os aqui chamados “exemplos para a compreensão”. É impossível, pois, não aludir ao problema da definição lexicográfica ao tratar esse tipo de exemplo no dicionário.

Uma "teoria (meta)lexicográfica integral" (cf. BUGUEÑO MIRANDA, 2019a, 2019b), por sua vez, possibilita entender o dicionário como um todo estruturado em partes que são, ao mesmo tempo, interdependentes e complementares. Esse modelo teórico integral, para que funcione perfeitamente, deve estar orientado - seguindo a tendência das pesquisas (meta)lexicográficas das últimas décadas (cf., por exemplo, WIEGAND, 1998; BERGENHOLTZ; TARP, 2003; ADAMSKA-SAŁACIAK, 2019) - pela figura do usuário, o que gera a necessidade de se pensar de forma mais cuidadosa a seleção e apresentação da informação nos níveis macro, micro e medioestrutural (cf., por exemplo, TARP, 2006; 2008; 2011; TARP; GOUWS, 2010; 2012). Assim pois, a funcionalidade das informações define-se, por um lado, com base na tríade tipo de dicionário-perfil do usuário-função(ões) da obra (cf. seção 2.1) e, por outro, em termos de discrição e discriminância das informações lexicográficas (cf. BUGUEÑO MIRANDA; FARIAS, 2006; 2008a). Uma informação discreta é aquela que corresponde efetivamente a um fato de norma - sendo norma aqui entendida como as realizações normais ou tradicionais no seio de uma dada comunidade linguística, em contraposição ao sistema, ou conjunto de possibilidades virtuais, não necessariamente realizadas (cf. COSERIU, 1967). Um exemplo de informação não discreta é a que se apresenta no pós-comentário do verbete do seguinte dicionário escolar: blitz "[Em alemão, com inicial maiúsc.]" (MiCA, 2004, s.v. blitz) $)^{5}$. Uma informação discriminante, por outro lado, é a que permite ao leitor obter algum proveito com relação ao uso e/ou conhecimento da língua. A título de ilustração, analisa-se o verbete morder "tr.-prnl. [algo, a alguien] Sujetar y apretar clavando los dientes: el niño muerde la manzana; un perro le mordió en la pierna" (DPELE, 2002, s.v. morder, ac.1). Em espanhol, o verbo morder exige complemento acusativo, como informa o próprio dicionário. Entretanto, o exemplo "leísta" apresentado após a definição (un perro LE mordió en la pierna, em lugar de un perro LO/LA mordió en la pierna), embora seja não apenas correto como também exemplar, ao menos do ponto de vista do standard europeu, pode gerar confusão para o aprendiz brasileiro de espanhol - público potencial do dicionário em questão.

No que concerne especificamente à exemplificação nos dicionários, a concepção de funcionalidade ajusta-se, ainda, à proposta de Harras (1989), segundo a qual, uma teoria do exemplo lexicográfico deveria agregar dois componentes:

a) componente descritivo: conjunto das relações sistemáticas estabelecidas entre os exemplos lexicográficos e os demais segmentos do verbete;

b) componente normativo: conjunto de critérios que permitam auferir a qualidade de um exemplo lexicográfico.

\subsection{A FUNCIONALIDADE DO EXEMPLO E O COMPONENTE DESCRITIVO}

A primeira variável - equivalente ao componente descritivo - consiste em determinar a necessidade do exemplo na microestrutura do dicionário - ou, em outras palavras, sua integração ao programa constante de informações (PCI). A necessidade do exemplo deveria definir-se (idealmente) a partir dos três parâmetros já mencionados: a definição taxonômica da

\footnotetext{
${ }^{5}$ Seguindo a tendência da metalexicografia europeia, para as citações de dicionários, em vez da Harvard Citation (autor ano: página), usaremos abreviaturas (cf. HARTMANN, 2001, p. 11). As referências completas dos dicionários, encabeçadas pelas respectivas siglas usadas no texto e ordenadas alfabeticamente, poderão ser encontradas na bibliografia final.
}

${ }^{6}$ Para uma visão geral do fenômeno do leísmo em espanhol, sua difusão do ponto de vista diatópico e avaliação dianormativa, cf. DPD (2005, s.v. leísmo). 
obra, o perfil do seu usuário e as funções que deve cumprir (cf. BUGUEÑO MIRANDA; FARIAS, 2008a, BUGUEÑO MIRANDA, 2019a).

A definição taxonômica de um dicionário consiste na sua classificação segundo um sistema de critérios pré-determinados, que possibilita, por conseguinte, atribuir traços específicos a um dado genótipo lexicográfico (cf. BUGUENO MIRANDA, 2014). Engelberg e Lemnitzer (2009, p. 19-23) apresentam uma proposta de classificação de obras lexicográficas que se apoia em quatro critérios fundamentais. O penúltimo deles - que evoca o conjunto de usuários ao qual se destina o dicionário - permite estabelecer uma oposição entre dicionário geral e dicionários com fins pedagógicos: enquanto as obras que se enquadram no primeiro grupo estão destinadas a um público mais amplo - ou difuso (cf. KÜHN, 1989) -, as que se classificam no segundo grupo destinam-se a um público mais específico - os aprendizes de uma língua, seja ela materna (abrangem os chamados "dicionários escolares") ${ }^{7}$ ou estrangeira (correspondem aos learner's dictionaries, ou dicionários para aprendizes) ${ }^{8}$.

O cruzamento das variáveis "definição taxonômica do dicionário" e "perfil do usuário", por sua vez, incide diretamente na apresentação de exemplos nas obras lexicográficas. Welker (2004, p. 157), a propósito, recorda que, para o usuário cuja língua do dicionário não é sua língua materna, as definições, independentemente do fato de estarem bem formuladas ou não, podem tornarse incompreensíveis; isso poderia explicar o emprego mais abundante de exemplos em learner's dictionaries do que em dicionários gerais. O usuário, entretanto, embora central no âmbito (meta)lexicográfico, continua sendo "o ilustre desconhecido" [der bekannte Unbekannte], conforme o definiu Wiegand (1977, p. 59) ${ }^{9}$. Nesse sentido, salienta-se que, pelo menos até o presente momento, não se dispõe de instrumentos que possam auxiliar na determinação empírica das necessidades dos consulentes, muito menos no reconhecimento de suas estratégias de busca - sobretudo se se trata de dicionários gerais ${ }^{10}$.

No que diz respeito às funções atribuíveis ao dicionário geral, este, na condição de dicionário semasiológico, deve encarregar-se primordialmente de auxiliar na compreensão linguística (cf. HAUSMANN, 1989). Ademais, diante da escassez de dicionários onomasiológicos - ou da inexistência de uma "cultura lexicográfica" que fomente o uso de obras desse tipo - poder-se-ia atribuir aos dicionários gerais uma função secundária de auxílio na produção linguística (cf. BUGUEÑO MIRANDA; FARIAS, 2008b, 2011c).

Em vista do exposto, o exemplo em dicionários gerais teria, por assim dizer, dois status diferentes:

a) segmento informativo integrante do comentário semântico ${ }^{11}$, nas situações em que é apresentado como um mecanismo complementar de elucidação do significado, devendo operar em conjunto com uma definição não elucidativa: a exemplificação serviria, nesse caso, à função de compreensão linguística (cf. FARIAS, 2008, 2013, p. 284-298; 335-347);

b) segmento informativo integrante do comentário de forma, destinado à apresentação de informações como a valência verbal, a regência verbal e nominal e as colocações: a exemplificação, aqui, estaria a serviço da função de produção linguística (cf. FARIAS, 2008, 2009, p. 129-163).

\footnotetext{
${ }^{7}$ Trata-se de uma designação genérica para todos os tipos de dicionários utilizados no contexto escolar, empregada aqui como medida de simplificação. Sobre os problemas designativos e conceituais no âmbito da lexicografia pedagógica de língua materna, cf. Tarp (2011).

${ }^{8}$ Para uma discussão acerca dos problemas designativos e conceituais relativos aos learner's dictionaries, cf. Bugueño Miranda e Jardim (2010).

${ }^{9}$ Welker (2006) apresenta um panorama das pesquisas sobre o uso de dicionários, considerando o uso efetivo e o efeito do uso de diferentes tipos de obras lexicográficas (destinadas a falantes nativos e não nativos), em diferentes âmbitos (compreensão de leitura, produção escrita, tradução, aprendizagem de vocabulário). Contudo, deve-se destacar que a maioria dos estudos teve como objeto línguas estrangeiras, em especial o inglês, de modo que faltam investigações sobre o uso de dicionários de língua materna.

${ }^{10}$ No caso dos dicionários destinados a aprendizes, Farias (2009) e Selistre (2012), por exemplo, propuseram o emprego, como medida paliativa, de documentos oficiais reguladores do ensino como referência para determinar as necessidades dos usuários, respectivamente, alunos do Ensino Fundamental ( $5^{\circ}$ ao $9^{\circ}$ ano) e alunos do Ensino Médio ( $1^{\circ}$ ao $3^{\circ}$ ano). Em ambos os casos, no entanto, foi possível apenas gerar perfis parciais dos respectivos usuários, uma vez que pouco ou nada se pôde dizer acerca das suas estratégias de busca.

${ }^{11}$ Wiegand (1989) divide formalmente a microestrutura em dois comentários fundamentais [Grundkommentare]: o comentário de forma [Formkommentar] e o comentário semântico [semantischer Kommentar]. O comentário de forma comporta informações relativas à representação gráfica e fonético-fonológica do signolema, enquanto o comentário semântico abriga informações referentes ao seu significado. Cf. também Bugueño Miranda (2004a).
} 
Há, por fim, uma terceira função do exemplo, que emerge em dicionários gerais exaustivos (cf. a classificação de WELKER, 2004, p. 44 ss.), ou em alguns tipos de dicionários especiais de orientação informativa, como o dicionário etimológico ou o dicionário histórico, ou de orientação por tipo de lema, como os dicionários de arcaísmos ou neologismos (cf. a classificação de ENGELBERG; LEMNITZER, 2009). Em obras como as mencionadas, os exemplos podem aparecer, como parte integrante do comentário etimológico (cf., a esse respeito, BUGUEÑO MIRANDA, 2004b), com a função exclusiva de atestar a ocorrência da unidade léxica correspondente.

\subsection{A FUNCIONALIDADE DO EXEMPLO E O COMPONENTE NORMATIVO}

A segunda variável - que fazemos corresponder ao componente normativo definido em Harras (1989) - requer considerar dois aspectos. O primeiro aspecto concerne à própria concepção de exemplo na microestrutura da obra lexicográfica, que nem sempre é completamente clara. Converte-se, portanto, em um imperativo definir de forma precisa o que é o chamado "exemplo lexicográfico", de maneira que se consiga opô-lo funcionalmente a outros segmentos informativos. O segundo aspecto envolve a atribuição de funções específicas ao segmento dedicado à exemplificação - auxiliar na compreensão linguística, auxiliar na produção linguística ou, ainda, atestar a existência de uma unidade léxica/uma acepção -, atrelando-as a distintos tipos de exemplos (autênticos ou inventados/adaptados).

\subsubsection{Problemas conceituais em torno do exemplo lexicográfico}

Humblé (1996) postula que "[a]n example is a kind of miniaturised context" cuja função é deslindar "a particular meaning of a word and its behaviour in specific linguistic surroundings". Contudo, a pretensa objetividade da definição apresentada em Humblé (1996) - e assumida igualmente em Humblé (1998, 2001) - dista muito de retratar a complexidade inerente ao tema.

Com efeito, Welker (2004, p. 150) destaca que o conceito de exemplo não é uma unanimidade entre os estudiosos. Garriga Escribano (2001) considera como exemplos na microestrutura do dicionário quaisquer excertos linguísticos - quer sejam sentenças completas, quer sejam apenas sintagmas - em que o signo-lema ocorra. Harras (1989) e Martin (1989) incluem também as colocações entre os exemplos.

Esse desacordo em relação ao conceito de exemplo reflete-se, igualmente, nas obras lexicográficas. Os dicionários da linha Collins COBUILD, por exemplo, utilizam preferencialmente sentenças completas para respaldar as informações linguísticas apresentadas nos verbetes. Essa forma de atuar, evidentemente, conforma-se à concepção de prática lexicográfica baseada em corpora que subjaz à elaboração dessas obras (cf. HUMBLÉ, 2001, p. 78-84). Todavia, não é incomum encontrar uma miscelânea de informações no segmento microestrutural correspondente à exemplificação, não só (embora principalmente) em dicionários bilíngues, mas também em dicionários monolíngues:

mísero adj. (sXIV) 1 muito pobre; miserável, paupérrimo $<$ no $m$. barraco viviam duas famílias $>2$ fig. pobre de ideias ou desprovido de inteligência <uns $m$. poemas $><$ escreveu um m. artigo para o jornal $>3$ muito reduzido; miserável, ínfimo, insignificante $<u m$ m. ordenado $><$ uma m. ajuda $>4$ sem valor ou importância; desprezível, insignificante, reles <não lhe deu um $m$. tostão de ajuda> $<$ por uns $m$. dez reais você pode ter a revista em sua casa $>$ [...] (HouE, 2009, s.v. mísero)

mòrte s. f. 1 Cessazione della vita, nell'uomo e in ogni organismo vivente: affrontare la m.; essere fra la vita e la m. | Darsi la m., uccidersi | Scherzare con la m., esporsi avventatamente ai pericoli | Sino alla m., per tutto il resto della vita | In caso di m., nell'eventualità che uno muoia | Questione di vita o di m., gravíssima, decisiva | Avere la m. nel cuore, nell'anima, essere molto addolorato $\mid$ Silenzio di m., profondo e terribile | Avercela a m. con qlcu., odiarlo profondamente; SIN. Decesso; CONTR. Vita. 2 Personificazione della morte | (est.) Ciò che uccide. 3 Pena capitale: sentenza di m.; 
condannare a m. 4 (fig.) Rovina, distruzione, fine: la m. di una industria. [...] (ZMiVLI, 2007, s.v. morte)

Em HouE (2009, s.v. mísero), apresentam-se sentenças completas e sintagmas no segmento reservado à exemplificação. No caso dos sintagmas, não fica claro se o dicionário pretende ressaltar uma particularidade referente ao emprego do signo-lema (o adjetivo mísero é usado preferencialmente anteposto ao substantivo), ou ilustrar colocações. De qualquer forma, o efeito obtido com a apresentação de sintagmas e de sentenças completas, no verbete em questão, é similar.

Outro tanto pode ser dito acerca de ZMiVLI (2007, s.v. morte). O segmento dedicado à exemplificação nesse dicionário comporta indicações diversas, como colocações (affrontare la morte; condannare a morte), locuções substantivas (sentenza di morte) e idioms (essere fra la vita e la morte). Não obstante, o PCI do dicionário abriga um segmento próprio dedicado à apresentação de unidades fraseológicas. Diante disso, é legítimo questionar os critérios que levaram os compiladores da obra a apresentar determinados frasemas como exemplos.

Welker (2004) declara-se abertamente contra a prática de registrar colocações e frasemas como exemplos, tendo em vista que ambos os tipos de sintagmas podem ser designados como tais. Concordamos, portanto, com o autor quando este define exemplos lexicográficos como "[...] enunciados (que podem ser abreviados) [...] tipograficamente distinguidos de outros elementos [...]" (WELKER, 2004, p. 150).

Toope (1996), por seu turno, defende - a nosso ver, com razão - que a apresentação de exemplos em forma de sintagma ou de sentença depende do propósito almejado. Nos casos em que se deseja ressaltar tendências de combinatórias léxicas, os sintagmas são mais apropriados, uma vez que "the restricted nature of the collocation may be obscured by extraneous information if it is given within a complete sentence” (TOOPE, 1996, p. 34). Por outro lado, informações semânticas, estilísticas e gramaticais poderiam ser apresentadas de forma mais apropriada por meio de sentenças completas.

\subsubsection{Tipos de exemplo lexicográfico e seus problemas designativos}

Svensén (2009, p. 283) classifica os exemplos lexicográficos em dois grupos: exemplos autênticos [authentic examples] ${ }^{12}$ - que Welker (2004) denomina abonações - e exemplos não autênticos [non-authentic examples] ou editorais [editorial examples], que se subdividem em exemplos adaptados [adapted examples] (tb. controlled examples [exemplos controlados], cf. HUMBLÉ, 1998) e exemplos inventados [invented examples] (tb. made-up examples, cf. HUMBLÉ, 1998).

De acordo com Martin (1989), os exemplos inventados - uma vez que são produzidos especialmente pelos lexicógrafos ou compiladores de obras dicionarísticas - não remetem, por assim dizer, ao "mundo real", assumindo, portanto, uma função meramente ilustrativa. Por outro lado, os exemplos autênticos, ao remeter a situações discursivas reais, encontram-se marcados histórica e ideologicamente, possuindo, portanto, valor enunciativo.

Ainda conforme Martin (1989), a partir dos exemplos autênticos, seria possível obter exemplos construídos, mediante um processo de simplificações sucessivas, denominado "neutralização" [neutralisation]: João passou dois longos dias transportando seus móveis/Ele transportou seus móveis/Ele transporta seus móveis/transportar os móveis/transportar algo ${ }^{13}$. Welker (2004), a esse respeito, postula que exemplos inventados deveriam corresponder exclusivamente a exemplos adaptados, conformando uma única categoria, posto que "[...] são inaceitáveis aqueles exemplos inventados que não poderiam ser exemplos adaptados, ou seja, tais que não se encontram no discurso real nem de forma parecida, frases que mostram um uso que só existe na cabeça do lexicógrafo" (WELKER, 2004, p. 156).

\footnotetext{
${ }^{12}$ No âmbito da tradição lexicográfica de língua inglesa, as evidências autênticas extraídas de corpora - cuja função é documentar o uso de uma acepção específica ou construção - são, em geral, denominadas quotations ou ainda, na América do Norte, tb. citations. Estas se opõem diametralmente aos examples [exemplos], aos quais se atribui a função de ilustrar um dado uso. A esse respeito, cf. Landau (2001, p. 207 - 211), Stein (2002, p. 205) e Simpson (2003, p. 267-272).

${ }^{13}$ Exemplo traduzido e adaptado de Martin (1989, p. 600).
} 
O embate entre defensores de exemplos autênticos, por um lado, e de exemplos inventados/adaptados, por outro, é uma constante no âmbito (meta)lexicográfico. John Sinclair e seus colaboradores defendem ferrenhamente a autenticidade dos exemplos nos dicionários da linha Collins COBUILD:

\begin{abstract}
According to John Sinclair, each sentence carries with it the characteristics of the text from which it was extracted. [...] Consequently, made-up examples are deceptive since the lexical or grammatical choices made in them do not depend on any text whatsoever. They can be 'grammatical,' but they are not 'natural' and it is not enough for learners to be able to produce sentences that are grammatically well formed. They must also be recognised as 'natural' by native speakers [...]. According to the Cobuild team, traditional lexicographers, being native speakers, make up examples that are grammatically acceptable, but because their intention is not to communicate anything other than information on a lexical item, this information is, strictly speaking, incorrect. Therefore, in these made-up examples, there is a chance that the words carry unwarranted negative connotations, that the collocates are wrong, and that the syntactic construction is correct yet unusual. In other words, a made-up example has no validity as a model. (HUMBLÉ, 2001, p. 79)
\end{abstract}

Em relação à posição extrema assumida pela equipe do Collins COBUILD, Welker (2004) objeta que o próprio John Sinclair cai em contradição ao afirmar que um exemplo só é completo quando corresponde a um texto inteiro. A frase na qual o signo-lema ocorre - que corresponde, em geral, à abonação apresentada nos dicionários - não constitui um texto inteiro; um texto inteiro, segundo Welker (2004), deve corresponder a um parágrafo ou mais. Os exemplos abonados, portanto, estariam descontextualizados (cf. WELKER, 2004, p. 155).

A crítica acerca da presumida falta de naturalidade - ou, em outras palavras, "atipicidade" - dos exemplos inventados/adaptados também merece ser rebatida. Svensén (2009, p. 284) sublinha que "[...] editorial examples are better than, or as good as, authentic ones, particularly in production: the necessary information is conveyed clearly and distinctly, without any distracting elements [...]". Humblé (2001, p. 81) relata seu experimento com aprendizes brasileiros de inglês, constatando que exemplos inventados/adaptados podem ser tão úteis quanto exemplos autênticos, e confirmando que os usuários dos dicionários, em geral, sequer atentam para a distinção entre ambos. Welker (2004, p. 157) acrescenta que:

É justamente a forma do exemplo que está no cerne da problemática da eficácia. Se opormos exemplos inventados ou adaptados, de um lado, e exemplos autênticos, do outro, ainda não está esclarecido se a forma dada aos primeiros é boa, mas podemos generalizar dizendo que, via de regra, as frases são sintaticamente mais simples e, muitas vezes mais breves. Assim, contrastam os exemplos autênticos, normalmente mais complexos, com os exemplos inventados/adaptados, menos complexos.

Diante disso, Calderón Campos (1994, p. 67) questiona se "naturalidade" e "claridade" não seriam, efetivamente, conceitos inconciliáveis. A esse respeito, no entanto, objetamos que uma correspondência entre exemplos inventados/adaptados e simplicidade, por um lado, e exemplos autênticos e complexidade, por outro, embora se verifique, efetivamente, em boa parte dos casos, não tem validez universal. A título de ilustração, comparam-se os excertos transcritos a seguir:

e [... 3. Adversativa: e no entanto, e contudo; e apesar disso: "O pior é que era coxa. Uns olhos tão lúcidos, uma boca tão fresca, uma compostura tão senhoril; $\underline{\mathrm{e}}$ coxa!" (Machado de Assis, Memórias Póstumas de Brás Cubas, p. 105.) [...] (AuE, 2009, s.v.e)

e [...] 2 Conjunção adversativa, quando liga idéias que não se coadunam e equivale a mas, contudo: Difamou o outro e bancou o ofendido. Fez mal e queixa-se. [...] (MiE, 1998, s.v. e)

Mesmo reconhecendo a provável subjetividade de nossa interpretação, permitimo-nos opinar que o exemplo autêntico de AuE (2009, s.v. e, ac.3) parece ser tão ou mais útil para o consulente do que o exemplo inventado/adaptado de MiE (1998, s.v. e, ac.2), 
uma vez que contextualiza o emprego da conjunção em questão com uma construção sintática simples, permitindo que o consulente compreenda seu emprego adversativo.

Por fim, em relação à "autoridade" conferida aos exemplos autênticos, é preciso considerar dois aspectos. Em primeiro lugar, Welker (2004, p. 153) pondera que não há garantias de que uma abonação possa refletir, verdadeiramente, o uso real; é possível que se trate de um hapax legomenon, ou mesmo de um uso encontrado várias vezes em um único autor, ou uma vez em poucos autores. Essa, aliás, é a impressão que se tem, muitas vezes, ao manusear o DUPB (2002), dicionário caracterizado por apresentar unicamente exemplos autênticos:

estrupiz Nm (Coloq) estrupício: Rebentava esse estrupiz (sangue animal e de gente) no mundo correndo, irosos, cavalos com feias faces (COB) (DUPB, 2002, s.v. estrupiz)

O registro de estrupiz é abonado com uma citação do romance Corpo de Baile, de João Guimarães Rosa (sigla COB). Além de não estar arrolada na nomenclatura nem de AuE (2009), nem de HouE (2009), a busca por ocorrências dessa unidade léxica em sites da internet retornou apenas 4 resultados, dois dos quais remetendo ao mesmo trecho do romance de João Guimarães Rosa citado no dicionário, enquanto os outros dois referem-se a usos metalinguísticos ${ }^{14}$. Há, portanto, fortes indícios de que se trate de um hapax legomenon.

Em segundo lugar, a indicação de abonações extremamente banais não acrescenta nada ao usuário, nem em relação à produção, muito menos em relação à compreensão linguística (cf. MARTIN, 1989; CALDERÓN CAMPOS, 1994; WELKER, 2004). A fim de endossar essa crítica, tomamos alguns excertos de verbetes relativos a compostos com a base love em CCLDe (2003):

love child [...] also love-child If journalists refer to someone as a love child, they mean that the person was born as a result of a love affair between two people who have never been married to each other. Eric has a secret love child. [...] (CCLDe, 2003, s.v. love child)

tug-of-love [...] Journalists sometimes use tug-of-love to refer to a situation in which the parents of a child are divorced and one of the parents tries to get the child from the other, for example by taking him or her illegally. (BRIT) A mother yesterday won a tug-of-love battle for custody of her twin daughters. [...] (CCLDe, 200, s.v. tug-of-love)

love life [...] Someone's love life is the part of their life that consists of their romantic and sexual relationships. His love life was complicated, and involved intense relationships. [...] (CCLDe, 2003, s.v. love life)

lovemaking [...] also love-making Lovemaking refers to sexual activities that take place between two people who love each other. Their love-making became less and less frequent. [...] (CCLDe, 2003, s.v. lovemaking)

Os exemplos apresentados nos verbetes love child e tug-of-love seriam, em princípio, dispensáveis, tendo em vista especificamente a à função de compreensão, posto que, em ambos os casos, as paráfrases podem ser consideradas bem formuladas ${ }^{15}$. Entretanto, as citações selecionadas podem contribuir para a tarefa de produção linguística, uma vez que indicam tendências colocacionais (p. ex., secret love child ${ }^{16}$, tug-of-love battle ${ }^{17}$ ).

\footnotetext{
${ }^{14}$ Consulta realizada com auxílio do buscador Google (domínio .br). Acesso em: dez. 2019.

${ }^{15}$ Sobre a relação entre formulação da definição e exemplos para compreensão linguística, cf. 2.2.2.1.

${ }^{16}$ A busca pela expressão secret love child retornou aproximadamente 33.100 resultados em consulta realizada com auxílio do buscador Google (domínio.uk). Acesso em: dez. 2019
} 
Os exemplos apresentados nos verbetes love life e lovemaking, por outro lado, não seriam úteis nem para a compreensão - outra vez estamos diante de paráfrases bem formuladas -, nem para a produção, pois não oferecem informações acerca de construções sintáticas específicas com o signo-lema, tampouco acerca de padrões colocacionais ${ }^{18}$.

Diante do panorama sucintamente exposto, fazemos eco às palavras de Calderón Campos (1994, p. 68): "[...] la polémica en torno a la autenticidad de los ejemplos me parece un problema secundario. Lo verdaderamente importante es que los ejemplos sean representativos, naturales, imitables [...] Si consiguen hacer todo esto, poco importará que sean inventados o reales” . Martin (1989), tomando como ponto de partida os distintos status atribuídos, respectivamente, aos exemplos autênticos e inventados/adaptados, complementa, de certa forma, a asserção anterior: “[...] l'exemple construit et l'exemple cité tendent aussi à ne pas remplir exactement les mêmes fonctions: l'un, par son dépouillement même se prête mieux, en général, aux exigences linguistiques. L'autre, comme énoncé effectif, a plutôt valeur philologique de témoignage.» (MARTIN, 1989, p. 601).

\subsubsection{Funções do exemplo nos dicionários gerais}

Embora a exemplificação encontre-se massivamente presente nas obras lexicográficas, a análise dos exemplos oferecidos em dicionários gerais de língua portuguesa, para restringirmo-nos apenas a esse caso, revela uma fragilidade (ou mesmo uma ausência) de critérios tanto na escolha das acepções que devem ser complementadas por essa informação como na própria formulação do segmento informativo (cf. FARIAS, 2008). Essa afirmação baseia-se no fato de que, à exceção de DUPB (2002) nesse caso, as abonações servem, em primeira instância, para atestar a ocorrência da unidade léxica/acepção registrada -, as demais obras - nominalmente, AuE (2009), HouE (2001, 2009) e MiE (1998) - apresentam exemplos somente para parte das acepções. É possível inferir, pois, que as obras citadas não consideram que todas as definições apresentadas necessitam de exemplificação.

Com relação especificamente aos dicionários de língua portuguesa mencionados, deslindam-se, ao menos, três problemas atinentes à apresentação dos exemplos:

a) ausência de critérios coerentes que fundamentem a seleção das acepções que realmente necessitam ser complementadas por um exemplo; como consequência, é frequente a apresentação de exemplos junto a acepções que não necessitariam de complementação, prescindindo-se de exemplificação em casos nos quais essa informação poderia ser útil para o consulente;

b) fornecimento de exemplos triviais, ou sem um contexto adequado; a utilidade da exemplificação como mecanismo explanatório complementar vê-se comprometida;

c) fornecimento de exemplos que não explicitam particularidades estilísticas/pragmáticas/sintáticas/colocacionais do signo-lema; nesse caso, o exemplo é inócuo em relação à tarefa de produção linguística.

A determinação da funcionalidade do exemplo lexicográfico começa pela definição precisa da sua função. Assim, o exemplo para compreensão cumpre o papel de ajudar na elucidação do significado, sendo que sua apresentação e formulação estão intimamente relacionadas com a definição à qual acompanha. O exemplo para produção, por outro lado, deve indicar o contexto sintático adequado da unidade léxica definida, levando em conta as possíveis necessidades/situações de consulta do usuário.

Por último, não obstante se possa assinalar uma terceira função para o exemplo lexicográfico, concordamos com Welker (2004, p. 152-153) em que a presença de abonações para atestar a ocorrência do signo-lema não constitui, em princípio, e considerando a definição taxonômica de obras deste tipo, uma informação funcional em dicionários gerais ${ }^{19}$.

\footnotetext{
${ }^{17}$ A busca pela expressão tug-of-love battle retornou aproximadamente 1.000 resultados em consulta realizada com auxílio do buscador Google (domínio.uk). Acesso em: dez. 2019.

${ }^{18}$ Em relação à produção linguística, o exemplo apresentado em CCLDe (2003, s.v. lovemaking) é, ademais, problemático: a abonação contradiz a indicação ortográfica, já que o signo-lema, na sentença apresentada como exemplo, ocorre justamente na forma considerada variante, portanto, provavelmente, de menos prestígio.
} 
O quadro apresentado a seguir sintetiza, segundo a nossa concepção, as funções que podem ser atribuídas aos exemplos, relacionando-as às possíveis formas que podem adotar e aos diferentes tipos aos quais podem corresponder:

\begin{tabular}{l|c|c|c}
\multirow{2}{*}{} & \multicolumn{2}{|c}{ Funções da exemplificação lexicográfica } \\
\cline { 2 - 4 } & Atestação da acepção & \multicolumn{2}{|c}{ Ilustração da acepção } \\
\cline { 2 - 4 } & Abonações & Para a compreensão & \multicolumn{2}{|c}{ Para a produção } \\
\cline { 2 - 4 } Formas da exemplificação & $\begin{array}{c}\text { Sentenças completas } \\
\text { (preferencialmente) }\end{array}$ & Sentenças completas & Sentenças completas e sintagmas \\
\hline \multirow{2}{*}{ Tipos de exemplificação } & Exemplos autênticos & $\begin{array}{c}\text { Exemplos autênticos, exemplos } \\
\text { inventados e exemplos } \\
\text { adaptados }\end{array}$ & $\begin{array}{c}\text { Exemplos inventados e } \\
\text { exemplos adaptados } \\
\text { (preferencialmente) }\end{array}$
\end{tabular}

Quadro 1: Relação entre formas, tipos e funções do exemplo lexicográfico

Fonte: elaboração própria

\subsubsection{Exemplos para compreensão}

Em Farias (2013, p. 335-348), propõe-se que o exemplo para compreensão deve corresponder a um tipo de mecanismo explanatório complementar.

A definição - embora seja o mecanismo explanatório por excelência e o recurso mais empregado nos dicionários, ao mesmo tempo em que corresponde a um dos tópicos sobre os quais mais se produzem estudos no âmbito (meta)lexicográfico - ainda carece de uma "teoria geral" (cf. BUGUEÑO MIRANDA, 2009a). Uma teoria geral da definição lexicográfica permitiria otimizar os resultados obtidos na redação de grande parte das paráfrases, minimizando - ou mesmo erradicando - os problemas metodológicos, como o círculo vicioso ou a formulação de construções obtusas (cf. BUGUEÑO MIRANDA; FARIAS, 2011a, 2011b; 2013a; 2013b; FARIAS, 2014, 2016, 2019), porém não poderia garantir a geração de paráfrases elucidativas na totalidade dos casos, uma vez que isso também depende, em boa medida, da natureza do significado da unidade léxica que se pretende definir (cf. FARIAS, 2013, p. 59-282; 2015, 2017). Em vista disso, faz-se necessário o emprego de mecanismos explanatórios secundários, que podem funcionar em conjunto com a paráfrase definidora, ou mesmo substituí-la ${ }^{20}$.

O primeiro passo relativo ao emprego de exemplos como mecanismos explanatórios complementares às paráfrases definidoras consiste na delimitação dos grupos de unidades léxicas às quais esse tipo de recurso poder-se-ia aplicar. Após uma análise exaustiva da natureza do significado de cada categoria morfológica, com vistas a determinar o tipo de paráfrase mais adequada em cada caso, Farias (2013, p. 289-291) discrimina os principais grupos de unidades léxicas cuja definição, em geral, não será elucidativa em virtude da complexidade do seu conteúdo semântico, e para as quais, portanto, um exemplo seria o recurso explanatório complementar mais adequado ${ }^{21}$ :

\footnotetext{
${ }^{19}$ Recorde-se, entretanto, que, em determinadas obras, a inclusão de abonações é praticamente uma conditio sine qua non. É o caso do dicionário histórico, cuja função é descrever o processo de desenvolvimento de cada palavra, desde seu aparecimento na língua, mediante recolha e citação de fontes literárias ou não literárias (cf. Martínez de Souza, 1995, s.v. diccionario histórico; Welker, 2004, p. 52-54).

${ }^{20}$ Outros mecanismos explanatórios complementares e/ou alternativos são as ilustrações e as notas de uso. A esse respeito, cf. Farias (2010a, 2010b, 2011).

${ }^{21}$ A delimitação dos grupos de unidades léxicas cujas paráfrases definidoras deveriam ser complementadas por exemplos está adequada a um dicionário geral de língua; poder-se-ia, no entanto, empregar exemplos para compreensão em verbetes de signos-lema que não correspondam exatamente aos grupos discriminados
} 
a) advérbios (mormente os que se definem em metalinguagem de signo) ${ }^{22}$;

b) conjunções (mormente as que se definem em metalinguagem de signo);

c) preposições (mormente as que se definem em metalinguagem de signo);

d) interjeições.

O segundo passo consiste em estabelecer critérios que permitam a geração de exemplos bem formulados - inclusive linguisticamente - tendo em vista a função que almejam cumprir. Os critérios que propomos são os seguintes:

a) Os exemplos para compreensão são parte do comentário semântico. Os exemplos, nesse caso, constituem mecanismos explanatórios complementares, de modo que devem, em todas as circunstâncias, acompanhar uma paráfrase não elucidativa, jamais substituí-la; as paráfrases, em forma de instruções de uso ${ }^{23}$, indicam ao usuário o(s) tipo(s) de relação estabelecido(s) pela conjunção/preposição em questão, ou o(s) contexto(s) em que o advérbio/a interjeição é empregado(a), e os exemplos complementares mostram ao consulente como o signo-lema funciona em um contexto determinado. A funcionalidade do exemplo é garantida pela relação de complementaridade estabelecida entre definição e exemplificação.

b) Os exemplos para compreensão podem ser autênticos ou inventados/adaptados, uma vez que a forma terá uma incidência muito maior do que o tipo de exemplificação no resultado final obtido: há tanto abonações como exemplos inventados/adaptados capazes de cumprir satisfatoriamente a função de auxiliar a compreensão linguística. Não obstante, e em vista das exigências sintáticas (cf. ad infra), poderia haver uma maior propensão à apresentação de exemplos inventados/adaptados.

c) Os exemplos para compreensão - principalmente tendo em vista as classes de palavras cujas definições ajudam a complementar - devem sempre ser apresentados sob a forma de sentenças completas, jamais de sintagmas. A sentença de exemplificação deve apresentar um contexto adequado, que permita ao usuário identificar a função que a paráfrase atribui à conjunção/à preposição/ao advérbio/à interjeição em questão. Além disso, deve, preferencialmente, apresentar-se sob a forma de um período simples ou composto, com orações, sempre que possível, na ordem direta (sujeito-verbo-objeto), e desprovido de elementos acessórios (adjuntos adverbiais etc.) desnecessários à compreensão.

A seguir, ilustramos alguns dos problemas concernentes à formulação de exemplos para compreensão:

ou [...] Conj. 1. Designa alternativa ou exclusão: vencer ou perecer; sim ou não. 2. Indica dúvida, incerteza ou hesitação: "o hipopótamo não me entendeu ou não me ouviu, se é que não fingiu uma dessas coisas" (Machado de Assis, Memórias Póstumas de Brás Cubas, p. 19); "Existe [Deus] ou não existe?" (Guimarães Passos, Versos de um Simples, p. 177). 3. De outro modo; por outra forma; por outra(s) palavra(s): mil metros, ou um quilômetro; tendência ou disposição de espírito; arte de fazer versos, ou poética; “- Chama-me Natureza ou Pandora” (Machado de Assis, Memórias Póstumas de Brás Cubas, p. 21). [...] (AuE, 2009, s.v. ou)

Em relação às definições, destacamos o fato de que AuE (2009, s.v. ou) alterna as técnicas empregadas. Na primeira e segunda acepções, encontramos uma paráfrase em metalinguagem de signo. Já na terceira acepção, o dicionário oferece uma reescrita em metalinguagem de conteúdo que não cumpre de forma completamente satisfatória o seu objetivo, já que a prova da substituição à qual a paráfrase deveria ser submetida não apresentaria como resultado orações aceitáveis; além disso, o significado não seria exatamente o mesmo. O ideal seria, pois, que o dicionário mantivesse a solução parafrástica oferecida nos dois primeiros casos.

acima, por exemplo, em dicionários pedagógicos destinados tanto a aprendizes da língua materna como de uma língua estrangeira, tendo em vista as possíveis limitações relativas ao domínio linguístico dos seus potenciais usuários.

${ }^{22}$ Aplicamos a oposição metalinguagem de conteúdo/metalinguagem de signo seguindo a proposta de Seco (2003).

${ }^{23}$ Sobre a formulação de paráfrases como instruções de uso em verbetes de conjunções e preposições, cf. Fornari (2009). 
No que tange aos exemplos, alguns deles não apresentam um contexto suficiente para que o leitor possa compreender com exatidão a noção expressa pela conjunção ou em uma situação determinada, como no caso do excerto "tendência ou disposição de espírito", que ilustra a terceira acepção.

De acordo com Bechara (2006, p. 321), a conjunção ou, considerada "a conjunção alternativa por excelência", pode exprimir tanto uma noção de incompatibilidade, quanto de equivalência. Com base nisso, elaborou-se uma proposta para a redação do verbete relativo à conjunção $o u^{24}$ :

ou conj 1. expressa uma relação de incompatibilidade entre dois sintagmas/dois enunciados: Susana precisava decidir se continuava casada com Ramiro ou se fugia com Otávio. Ou fazes bem o trabalho ou não o faças. 2. expressa uma relação de equivalência entre dois sintagmas/dois enunciados: O espanhol ou castelhano é língua oficial em diversos países.

\subsubsection{Exemplos para produção}

O primeiro passo em relação à apresentação de exemplos para produção - de forma similar ao que ocorre com os exemplos para compreensão - consiste em determinar quando se deve empregá-los. Farias (2008, p. 116-119; 2009, p. 146-153) propõe que eles poderiam ser extremamente úteis nos seguintes $\operatorname{casos}^{25}$ :

a) verbos (apresentação da valência verbal; apresentação da regência verbal);

b) substantivos e adjetivos (apresentação da regência nominal);

c) adjetivos relacionais (indicação dos substantivos que podem combinar-se com o adjetivo);

d) colocações.

Em seguida, procurou-se estabelecer critérios para a geração dos exemplos:

a) Os exemplos para produção são parte do comentário de forma do verbete e sua função é apresentar diversos tipos de informação, considerando o signo-lema cujo verbete integram: valência verbal, regência verbal e nominal, restrição de atribuição de adjetivos e colocações, entre outros passíveis de serem definidos. Especialmente nos casos em que se indica a valência verbal e a regência verbal e nominal, o segmento dedicado à exemplificação é redundante, na medida em que esses tipos de informações podem ser apresentados - e normalmente o são - em outros segmentos no interior do verbete, fator que aumenta a densidade do $\mathrm{PCI}^{26}$. A funcionalidade do exemplo é obtida pela possibilidade de correlacionar corretamente os distintos segmentos microestruturais destinados a indicar um mesmo tipo de informação.

b) Os exemplos para produção deveriam ser, idealmente, inventados/adaptados: nesses casos, pode-se controlar a formulação linguística, com vistas a destacar a informação sintática que se deseja apresentar.

c) Os exemplos para produção - cujo principal objetivo é a indicação de informações morfossintáticas e sintáticas - podem ser apresentados tanto sob a forma de sentenças completas como sob a forma de sintagmas. No caso das sentenças completas,

\footnotetext{
${ }^{24}$ Os modelos de verbetes apresentados nesta e na próxima seção foram criados a partir de sentenças encontradas em sites da internet, com o auxílio do buscador Google (domínio .br). A apresentação de exemplos em dicionários de língua poderia ser otimizada com o emprego de programas computacionais para análise e extração de material léxico. Sobre a geração de critérios para a seleção de "bons exemplos" a partir de corpora por meio de ferramentas informatizadas , cf. Didakowski, Lemnitzer e Geyken (2012), Kosem (2017), Kosem et al. (2019), Gantar et al. (2019) e Klosa-Kückelhaus e Müller-Spitzer (2019).

${ }^{25}$ A delimitação dos casos em que se deve empregar exemplos para produção é feita, aqui, de forma muito genérica, tendo em vista os dicionários gerais de língua. Como ocorre com os exemplos para compreensão, a necessidade de emprego de exemplos para produção varia em dicionários pedagógicos, tendo em vista o potencial público-alvo dessas obras. Além disso, nada obsta a que estudos posteriores apontem a necessidade de emprego de exemplos para produção em outras situações, mesmo em dicionários gerais, a partir do desenvolvimento de estudos mais aprofundados acerca do usuário desse tipo de obras.

${ }^{26}$ Bugueño Miranda (2009b, p. 62-63) estabelece uma diferença entre extensão e densidade do PCI. A extensão corresponde ao número de segmentos informativos definido para cada categoria morfológica. A densidade, por sua vez, diz respeito ao modo como cada segmento informativo é preenchido.
} 
devem apresentar-se, preferencialmente, sob a forma de um período simples, na ordem direta (sujeito-verbo-objetocomplementos circunstanciais).

A título de ilustração, tratar-se-á, a seguir, de alguns problemas atinentes à formulação de exemplos para produção em verbetes de adjetivos relacionais e verbos.

Os adjetivos relacionais não denotam uma qualidade ou propriedade específica dos substantivos, como os adjetivos qualificativos, mas um conjunto de propriedades (cf. DEMONTE, 1999, p. 136-141). Por essa razão, os dicionários costumam apresentar, nos verbetes correspondentes a adjetivos relacionais, uma série de distintos matizes de significação:

estudantil [...] 1. de estudante: [...] documentos de identidade e carteira estudantil [...]; [...] com relação a moradias estudantis [...]. 2. que estuda; estudante: [...] a colaboração ativa da juventude estudantil; [...] nas nossas universidades cuja população estudantil atualmente [...]. 3. dos estudantes: [...] ligada às reivindicações estudantis [...]; Sobre o problema estudantil [...]. 4. característico de quem é estudante: uma referência estudantil [...]. (DUPB, 2002, s.v. estudantil)

O significado de adjetivos relacionais, em um dado contexto, é determinado, em parte, pelo substantivo que os acompanha. A melhor solução, portanto, seria oferecer uma definição em metalinguagem de signo, indicando o campo semântico que o adjetivo abrange, e apresentar alguns exemplos de substantivos aos quais o adjetivo em questão pode unir-se. Dessa forma, além de o consulente ter uma noção aproximada dos contextos sintáticos em que o vocábulo pode aparecer, também terá a possibilidade de identificar alguns matizes de significação. Em verbetes de adjetivos, julga-se suficiente a apresentação de sintagmas ${ }^{27}$ :

estudantil adj [algo/alguém] relativo aos estudantes: movimento estudantil; assistência estudantil; carteira estudantil; financiamento estudantil; grêmio estudantil; líder estudantil; diretor estudantil

Analisamos, por fim, alguns verbetes de verbos:

$\operatorname{arcar}^{2}[\ldots]$ 3. Responder por; responsabilizar-se: $\underline{\operatorname{arcar}}$ com o prejuízo. [...] (AuE, 2009, s.v. $\operatorname{arcar}^{2}$ )

propender $[\ldots]$ 2. [...] ter tendência, pendor ou gosto para (algo); inclinar-se, tender. Ex.: <ele propende mais para as artes do que para a ciência $><$ os jurados propendiam a absolver o réu $>$ (HouE, 2009, s.v. propender)

$\operatorname{AuE}\left(2009\right.$, s.v. $\operatorname{arcar}^{2}$, ac. 3) classifica esse verbo como transitivo indireto, fornecendo um exemplo que indica a preposição adequada para construí-lo, sem deixar dúvidas ao consulente. HouE (2009, s.v. propender, ac. 2), a exemplo do que faz AuE (2009, S.v. $\operatorname{arcar}^{2}$ ), classifica o verbo como transitivo indireto e também apresenta exemplos que ilustram duas construções distintas, indicando ao consulente as duas preposições que podem aparecer com o verbo propender. Além disso, salientamos o fato de que as orações apresentadas para exemplificação estão na ordem direta, o que facilita a identificação dos respectivos actantes. Por fim, a paráfrase definidora, muito embora apresente problemas evidentes de redação, procura informar ao leitor a valência do verbo, deixando uma lacuna que deve ser preenchida no contexto.

Assumindo como ponto de partida as propostas de AuE (2009) e HouE (2001), formularam-se os seguintes modelos para a apresentação de exemplos para produção em verbetes de verbos:

\footnotetext{
${ }^{27}$ Bargalló Escrivá (2008, p. 490), ao analisar dicionários pedagógicos de língua espanhola, dirigidos a aprendizes de espanhol como língua materna ou como língua estrangeira, constata que há uma regularidade no emprego de exemplos sob a forma de sintagmas em verbetes de adjetivos relacionais, sendo que, nesses casos, é habitual indicar "un sintagma en el que el adjetivo figura detrás del sustantivo dado que esta es la única posición que puede ocupar, salvo para aquellos casos en los que puede recategorizarse como calificativo”.
} 
arcar $v+$ prep 1. assumir a responsabilidade por [algo]: João arcou com os custos da viagem. A prefeitura arcará com as despesas da obra.

propender $v+$ prep 1. ter inclinação por [algo]: A natureza humana propende para o mal. O governo propende a uma solução menos radical.

\section{CONSIDERAÇÕES FINAIS}

No presente artigo, propuseram-se os fundamentos do que poderia vir a ser uma teoria do exemplo lexicográfico. Tomaram-se como base para a discussão os postulados de Harras (1989) e estabeleceu-se como objetivo a sistematização da apresentação da exemplificação em dicionários semasiológicos - mormente, os dicionários gerais de língua -, a fim de convertê-la em uma informação funcional. A discussão levada a cabo pode ser sintetizada em dois tópicos. Primeiramente, os exemplos convertem-se em informações funcionais na microestrutura ao estabelecer-se critérios que possibilitem distinguir entre signos-lema que não necessitam de exemplificação (nem para compreensão, nem para produção), signos-lema que necessitam de exemplificação para compreensão e signos-lema que necessitam de exemplificação para produção. Em segundo lugar, os exemplos convertem-se em informações funcionais na microestrutura ao desenvolver-se técnicas diferenciadas para sua elaboração, tendo em vista, em primeiro lugar, a finalidade da exemplificação (compreensão ou produção), e, em segundo lugar, as particularidades de cada grupo de palavras, bem como as possíveis dificuldades que possam representar para os usuários.

\section{REFERÊNCIAS}

ADAMSKA-SAŁACIAK, A. Lexicography and Theory: Clearing the Ground. International Journal of Lexicography, Oxford, 32, v. 1, p. 1-19. 2019.

AuE. Ferreira, A. B. de H. Novo dicionário Aurélio da língua portuguesa. 4. ed. Curitiba: Positivo, 2009.

BARGALLÓ ESCRIVÁ, M. El programa de ejemplificación en los diccionarios didácticos. In: BERNAL GALLÉN, E.; DECESARIS, J. (org.). Proceedings of the XIII Euralex International Congress on Lexicography. Barcelona: Institut Universitari de Lingüística Aplicada, 2008. p. 489 - 494

BECHARA, E. Moderna gramática portuguesa. 37. ed. Rio de Janeiro: Lucerna, 2006.

BERGENHOLTZ, H.; TARP, S. Two opposing theories: On H. E. Wiegand's recent discovery of lexicographic functions. Hermes Journal of Linguistics, Aarhus, n. 31, p. 171-196, 2003.

BUGUEÑO MIRANDA, F. V. Notícia sobre o comentário de forma e o comentário semântico em um dicionário de falsos amigos espanhol-português. Expressão, Santa Maria, v. 8, n.1, p. 89-93. 2004a.

BUGUEÑO MIRANDA, F. V. La etimología en el diccionario de la lengua. Revista Letras, Curitiba, n. 64, p. 173-188. 2004b. Disponível em: http://ojs.c3sl.ufpr.br/ojs2/index.php/letras/article/viewArticle/2976. Acesso em: 15 dez. 2019.

BUGUEÑ MIRANDA, F. V. Para uma taxonomia de paráfrases explanatórias. Alfa, São Paulo, n. 53, v. 1, p. 243-260, 2009 a. 
BUGUEÑO MIRANDA, F. V. Sobre a microestrutura em dicionários semasiológicos do alemão. Contingentia, Porto Alegre, v. 4 , n. 2, p. 60-72, 2009b. Disponível em: http://www.lume.ufrgs.br/bitstream/handle/10183/20868/000726263.pdf?sequence=1. Acesso em: 30 jul. 2011.

BUGUEÑO MIRANDA, F. V. Da classificação de obras lexicográficas e seus problemas: proposta de uma taxonomia. Alfa, São Paulo, n. 58, v. 1, p. 215-231, 2014.

BUGUEÑO MIRANDA, F. V. Princípios teóricos básicos do manual. In: BUGUEÑO MIRANDA, F. V.; BORBA, L. C. (ed.). Manual de (Meta)Lexicografia. Goiânia: Editora Espaço Acadêmico, 2019a. p. 13-14.

BUGUEÑO MIRANDA, F. V. A estruturação de um dicionário. In: BUGUEÑO MIRANDA, F. V.; BORBA, L. C. (ed.). Manual de (Meta)Lexicografia. Goiânia: Editora Espaço Acadêmico, 2019b. p. 17-32.

BUGUEÑO MIRANDA, F. V.; FARIAS, V. S. Informações discretas e discriminantes no artigo léxico. Cadernos de Tradução, Florianópolis, n. 18, p. 115-135, 2006.

BUGUEÑO MIRANDA, F. V.; FARIAS, V. S. Desenho da macroestrutura de um dicionário escolar de língua portuguesa. In: BeVIlaCQUA, C. R.; HUMBlÉ, P.; XATARA, C. (ed.). Lexicografia Pedagógica: Pesquisas e perspectivas. Florianópolis: UFSC/NUT, 2008a. p. 129-167. Disponível em: http://www.cilp.ufsc.br/LEXICOPED.pdf. Acesso em: 25 out. 2008.

BUGUEÑO MIRANDA, F. V.; FARIAS, V. S. O ensino de português e os dicionários escolares: Um segmento informativo da microestrutura para fins de produção textual. Polifonia, Cuiabá, n. 15, p. 1-14, 2008 b.

BUGUEÑO MIRANDA, F. V.; FARIAS, V. S. Princípios para o desenvolvimento de uma teoria da definição lexicográfica. Alfa, São Paulo, n. 55, v. 1, p. 31-61, 2011a.

BUGUEÑO MIRANDA, F. V.; FARIAS, V. S. Sobre las palabras y su clasificación según su contenido. Los problemas para el lexicógrafo. Revista de Filología de la Universidad de La Laguna, La Laguna, n. 29, p. 9-19, 2011 b.

BUGUEÑO MIRANDA, F. V.; FARIAS, V. S. Da microestrutura em dicionários semasiológicos do português e seus problemas. Estudos da Lingua(gem), Vitória da Conquista, v. 9, p. 36- 69, 2011c.

BUGUEÑO MIRANDA, F. V.; FARIAS, V. S. Los subsidios de tres teorías semánticas para la generación de definiciones lexicográficas. Revista de Filología de la Universidad de La Laguna, La Laguna, n. 31, p. 19-34, 2013 a.

BUGUEÑO MIRANDA, F. V.; FARIAS, V. S. Teorías semánticas y definición lexicográfica. Análisis de las paráfrasis explicativas de los diccionarios generales de lengua española. Cadernos de Tradução, Florianópolis, n. 32/2, p. 183-225. 2013 b.

BUGUEÑO MIRANDA, F. V.; JARDIM, C. R. Os learner's dictionaries do inglês e os Lernwörterbücher do alemão: uma simples transposição de nomes? Contingentia, Porto Alegre, v. 5, n. 1, p. 41 - 67, 2010 . Disponível em: http://seer.ufrgs.br/contingentia/article/view/13319/7614. Acesso em: 22 jul. 2011.

CALDERÓN CAMPOS, M. Sobre la elaboración de diccionarios monolingües de producción. Las definiciones, los ejemplos y las colocaciones léxicas. Granada: Servicio de Publicaciones de la Universidad de Granada, 1994.

CCLDe. SINCLAIR, J. Collins COBUILD Advanced Learner's Dictionary. Glasgow: HarperCollins, 2003.

COSERIU, E. Sistema, norma y habla. In: COSERIU, E. Teoría del lenguaje y lingüística general. Cinco estudios. 2. ed. Madrid: Gredos, 1967.p. 11-113. 
DEMONTE, V. El adjetivo: Clases y usos. La posición del adjetivo en el sintagma nominal. In: BOSQUE, I.; DEMONTE, V. (dir.). Gramática descriptiva de la lengua española. Madrid: Espasa Calpe, 1999. p. 129-215.

DIDAKOWSKI, J.; LEMNITZER, L.; GEYKEN, A. Automatic example sentence extraction for a contemporary German dictionary. In: FJELD, R. V.; TORJUSEN, J. M. (ed.). Proceedings of the XV Euralex International Congress of Lexicography. Oslo: Department of Linguistics and Scandinavian Studies, 2012. p. 343-349.

DPD. REAL ACADEMIA ESPAÑOLA. Diccionario panhispánico de dudas. Madrid: Espasa-Calpe, 2005. Disponível em: https://www.rae.es/dpd/. Acesso em: 20 maio 2020.

DPELE. UNIVERSIDAD DE ALCALÁ DE HENARES. Señas: diccionario para la enseñanza de la lengua española para brasileños. 2. ed. São Paulo: Martins Fontes, 2002.

DUBOIS, J.; DUBOIS, C. Introduction à la lexicographie: le dictionnaire. Paris: Librairie Larousse, 1971.

DUPB. BORBA, F. da S. Dicionário de usos do português do Brasil. São Paulo: Ática, 2002.

ENGELBERG, S.; LEMNITZER, L. Lexikographie und Wörterbuchbenutzung. 4. Aufl. Tübingen: Stauffenburg, 2009.

FARIAS, V. S. O exemplo como informação discreta e discriminante em dicionários semasiológicos de língua portuguesa. Alfa, São Paulo, n. 52, v. 1, p. 101-122, 2008.

FARIAS, V. S. Desenho de um dicionário escolar de língua portuguesa. 2009. 286 f. Dissertação (Mestrado em Lexicografia e Terminologia) - Instituto de Letras, Universidade Federal do Rio Grande do Sul, Porto Alegre, 2009.

FARIAS, V. S. Fundamentos para uma teoria geral dos mecanismos explanatórios: Objetivos, metodologia e primeiros resultados da pesquisa. Cadernos do IL (UFRGS), Porto Alegre, n. 40, p. 45-65, 2010a. Disponível em: http://seer.ufrgs.br/cadernosdoil/article/view/24900. Acesso em: 17 ago. 2012.

FARIAS, V. S. O emprego de ilustrações como mecanismos de elucidação do significado das unidades léxicas nos dicionários semasiológicos. In: RAUEN, F. J. (ed.). Anais do IX Encontro do CELSUL. Palhoça: Editora da Unisul, 2010b. p. 1-19. Disponível em: http://www.celsul.org.br/Encontros/09/artigos/Virginia\%20Farias.pdf. Acesso em: 22 jul. 2012.

FARIAS, V. S. Considerações preliminares sobre o pós-comentário na microestrutura de dicionários semasiológicos. ReVEL, Porto Alegre, $\quad$ v. $9, \quad$ n. $17, \quad$ p. 109-139, 2011 . Disponível em: http://www.revel.inf.br/files/artigos/revel 17 consideracoes preliminares.pdf. Acesso em: 07 jan. 2013.

FARIAS, V. S. Sobre a definição lexicográfica e seus problemas. Fundamentos para uma teoria geral dos mecanismos explanatórios em dicionários semasiológicos. 2013. 399 f. Tese (Doutorado em Lexicografia e Terminologia) - Instituto de Letras, Universidade Federal do Rio Grande do Sul, Porto Alegre, 2013.

FARIAS, V. S. O legado das teorias lexicológicas tradicionais para a práxis lexicográfica: uma discussão sobre a metalinguagem da definição (com ênfase nos dicionários de língua espanhola). Caligrama: Revista de Estudos Românicos, Belo Horizonte, v. 19, p. 151-177, 2014

FARIAS, V. S. A descrição de palavras gramaticais em dicionários semasiológicos: O estado da arte na prática lexicográfica e projeções para o futuro. In: CNLF - Congresso Nacional de Linguística e Filologia, 19., 2015, Rio de Janeiro. Cadernos do CNLF Lexicografia, lexicologia, fraseologia, terminologia e semântica. Rio de Janeiro: CiFEFiL, 2015. p. 54-76. 
FARIAS, V. S. Relação entre princípios de redação das definições e metalinguagem lexicográfica. Uma análise crítica. Raído, Dourados, v. 10, p. 108-131, 2016.

FARIAS, V. S. ¿Cómo definir sustantivos que designan sentimientos/emociones? Análisis de paráfrasis y apreciación de propuestas para su perfeccionamiento. Revista de Estudos da Linguagem, Belo Horizonte, v. 25, p. 179-216, 2017.

FARIAS, V. S. A definição. In: BUGUEÑO MIRANDA, F. V.; BORBA, L. C. (eds.). Manual de (Meta)Lexicografia. Goiânia: Editora Espaço Acadêmico, 2019. p. 126-129.

FORNARI, M. K. O tratamento lexicográfico das palavras gramaticais: discussão teórica e análise de verbetes. Revista Travessias, Cascavel, n. 3/3, p. 167-199, 2009. Disponível em: http://e-revista.unioeste.br/index.php/travessias/article/view/3463/2757. Acesso em: 15 fev. 2013.

FOURMENT-BERNI CANANI, M. Neutralisation, cumul et généralisation en lexicographie bilingue (domaine Français-Italien). In: FERRARIO, E.; POLCINI, V. (eds.). La lessicografia bilingue tra presente e avvenire. Vercelli: Mercurio, 2002. p. 49-63.

FRANKENBERG-GARCÍA, A. Dictionaries and Encoding Examples to Support Language Production. International Journal of Lexicography, Oxford, v. 28, n. 4, p. 490-512, 2015.

GANTAR, P. et al. Multiword Expressions: Between Lexicography and NLP. International Journal of Lexicography, Oxford, v. 32 , n. 2, p. 138-162, 2019.

GARRIGA ESCRIBANO, C. Los ejemplos en los diccionarios didácticos del español. In: AYALA CASTRO, M. C. (org.). Diccionarios y enseñanza. Alcalá de Henares: Universidad de Alcalá, 2001.p. 127-149.

GARRIGA ESCRIBANO, C. La microestructura del diccionario: las informaciones lexicográficas. In: MEDINA GUERRA, A. M. (org.). Lexicografía española. Barcelona: Ariel, 2003. p. 103-126.

HARRAS, G. Zu einer Theorie des lexikographischen Beispiels. In: HAUSMANN, F. J. et al. (Hrsgn.). Wörterbücher, Dictionaries, Dictionnaires. Ein internationales Handbuch zur Lexikographie. Band 1. Berlin/New York: Walter de Gruyter, 1989. p. 607-614.

HARTMANN, R. R. K. Teaching and Researching Lexicography. London: Longman, 2001.

HARTMANN, R. R. K.; JAMES, G. Dictionary of lexicography. London/New York: Routledge, 2001.

HAUSMANN, F. J. Das Definitionswörterbuch. In: HAUSMANN, F.J. et al. (Hrsgn.) Wörterbücher, Dictionaries, Dictionnaires. Ein internationales Handbuch zur Lexikographie. Band 1. Berlin/New York: Walter de Gruyter, 1989. p. 981-988.

HEINZ, M. L'exemple lexicographique à function culturelle dans le Robert pour tous. Revue Internationale de Didactologie des Langues et des Cultures, Paris, n. 128, p. 413-430, 2002.

HERBST, T.; KLOTZ, M. Lexikografie. Paderborn: Ferdinand Schöningh, 2003.

HILES, L. Categorising Example Sentences in Dictionaries for Research Purposes. Lexikos, Stellenbosch, v. 21, p. 298-304, 2011.

HouE. HOUAISS, A. Dicionário Houaiss da língua portuguesa. Rio de Janeiro: Objetiva, 2001.

HouE. HOUAISS, A. Dicionário Houaiss da língua portuguesa. Rio de Janeiro: Objetiva, 2009. 
HUMBLÉ, P. Examples in bilingual dictionaries. In: AILA Word Congress, 11, 1996, Yyväskylä. Proceedings... Yyväskylä: s.n., 1996. p. 1-6.

HUMBLÉ, P. The use of authentic, made-up and controlled examples in foreign language dictionaries. In: FONTENELLE, T. et al. (ed.). Proceedings of the VIII Euralex International Congress of Lexicography. Liège: Université de Liège, 1998. p. 593-600.

HUMBLÉ, P.Dictionaries and language learners. Frankfurt am Main: Haag und Herchen, 2001.

JESENŠEK, V. Das lexikographische Beispiel in der Parömiographie. Formen und Funktionen. Lexikos, Stellenbosch, v. 23, p. 150-171, 2013.

KLOSA-KÜCKELHAUS, A.; MÜLLER-SPTIZER, C. OWID und OWIDplus: lexikographische und lexikalische Ressourcen am IDS Mannheim. Zeitschrift für germanistische Linguistik, Berlin/Boston, v. 47, n. 2, 418-431, 2019.

KLOTZ, M.; HERBST, T. English Dictionaries. A Linguistic Introduction. Berlin: Erich Schmidt Verlag, 2016.

KOSEM, I. Dictionary examples. In: GORJANC, V. et al. (ed.). Dictionary of Modern Slovene: Problems and Solutions. Ljubljana: Ljubljana University Press, 2017. p. 174-193.

KOSEM, I. et al. Identification and automatic extraction of good dictionary examples: the case(s) of GDEX. International Journal of Lexicography, Oxford, v. 32, n. 2, p. 119-137, 2019.

KÜHN, P. Typologie der Wörterbücher nach Benutzungsmöglichkeiten. In: HAUSMANN, F. J. et al. (Hrsgn.). Wörterbücher, Dictionaries, Dictionnaires. Ein internationales Handbuch zur Lexikographie. Band 1. Berlin/New York: Walter de Gruyter, 1989. p. 111-127.

LANDAU, S. Dictionaries. The art and craft of lexicography. 2. ed. Cambridge: Cambridge University Press, 2001.

LETTNER, K. Zur Theorie des lexikographischen Beispiels. Die Beispielangaben in der ein- und zweisprachigen pädagogischen Lexikographie des Deutschen. Berlin/Boston: Walter de Gruyter, 2020.

LIU, X. Multimodal Exemplification: The Expansion of Meaning in Electronic Dictionaries. Lexikos, Stellenbosch, v. 27, p. $287-$ $309,2017$.

MARTIN, R. L'exemple lexicographique dans le dictionnaire monolingue. In: HAUSMANN, F. J. et al. (Hrsgn.). Wörterbücher, Dictionaries, Dictionnaires. Ein internationales Handbuch zur Lexikographie. Band 1. Berlin/New York: Walter de Gruyter, 1989. p. 599-607.

MARTÍNEZ DE SOUZA, J. Diccionario de lexicografía práctica. Barcelona: Bibliograf, 1995.

MERZAGORA, G. La lessicografia. Bologna: Zanichelli, 1987.

MiCA. CALDAS AULETE, F. J. Minidicionário contemporâneo da língua portuguesa. Rio de Janeiro: Nova Fronteira, 2004.

MiE. MICHAELIS. Moderno dicionário da língua portuguesa. São Paulo: Melhoramentos, 1998.

MINAEVA, L. Dictionary examples: friends or foes? In: TOMMOLA, H. et al. (ed.). Proceedings of the V Euralex International Congress of Lexicography. Tampere: University of Tampere, 1992. p. 77-80. 
OSSELTON, N. E. Quotation and Example in Johnson's Abridged Dictionary (1756-78). International Journal of Lexicography, Oxford, v. 31, n. 4, p. 475-484, 2018.

POTGIETER, L. Example sentences in bilingual school dictionaries. Lexikos, Stellenbosch, v. 22, p. 261-271, 2012.

REY-DEBOVE, J. Étude linguistique et sémiotique des dictionnaires français contemporains. Paris: Mouton, 1971.

ROBLES I SABATER, F. ¿Qué es un buen ejemplo? La ejemplificación en la teoría lexicográfica alemana. Revista de Filología Alemana, Madrid, v. 19, p. 247-261, 2011.

SECO, M. Estudios de Lexicografía Española. 2. ed. Madrid: Gredos, 2003.

SELISTRE, I. C. T. Desenho de um dicionário passivo inglês/português para estudantes do ensino médio. $2012.301 \mathrm{f}$. Tese (Doutorado em Lexicografia e Terminologia) - Instituto de Letras, Universidade Federal do Rio Grande do Sul, Porto Alegre, 2012 .

SIMPSON, J. The production and use of occurrence examples. In: STERKENBURG, P. von. (ed.). A practical guide to Lexicography. Amsterdam/Philadelphia: John Benjamins, 2003. p. 260-272.

STEIN, G. Exemplification in EFL Dictionaries. In: STEIN, G. (ed.). Better Words. Evaluation EFL Dictionaries. Exeter: University of Exeter Press, 2002. p. 204-229.

SVENSÉN, B. A Handbook of Lexicography. The Theory and Practice of Dictionary-Making. Cambridge: Cambridge University Press, 2009.

TARP, S. Lexicografía de aprendizaje. Cadernos de Tradução, Florianópolis, n. 18, p. 295-317, 2006.

TARP, S. Lexicography in the Borderland between Knowledge and Non-Knowledge. Tübingen: Max Niemeyer Verlag, 2008.

TARP, S. Pedagogical lexicography: Towards a new and strict typology corresponding to the present state-of-the-art. Lexikos, Stellenbosch, v. 21, p. 217-231, 2011.

TARP, S.; GOUWS, R. H. Skoolwoordeboeke vir huistaalleerders van Afrikaans. Lexikos, Stellenbosch, v. 20, p. 466-494, 2010.

TARP, S.; GOUWS, R. H. School dictionaries for first-language learners. Lexikos, Stellenbosch, v. 22, p. 333-351, 2012.

TOOPE, M. Examples in the bilingual dictionary, 1996, 253 f. Thesis (Degree of M.A. in Translation) - School of Graduate Studies and Research, University of Ottawa, Ottawa, 1996.

WELKER, H. A. Dicionários. Uma pequena introdução à lexicografia. 2. ed. Brasília: Thesaurus, 2004.

WELKER, H. A. O uso de dicionários. Brasília: Thesaurus, 2006.

WIEGAND, H. E. Nachdenken über Wörterbücher: Aktuelle Probleme. In: DROSDOWSKY, G. (Hrsg.). Nachdenken über Wörterbücher. Mannheim: Bibliographisches Institut, 1977. p. 51-102.

WIEGAND, H. E. Der Begriff der Mikrostruktur: Geschichte, Probleme, Perspektiven. In: HAUSMANN, F. J. et al. (Hrsgn.). Wörterbücher, Dictionaries, Dictionnaires. Ein internationales Handbuch zur Lexikographie. Band 1. Berlin/New York: Walter de Gruyter, 1989. p. 409-462. 
WIEGAND, H. E. Wörterbuchforschung. Untersuchungen zur Wörterbuchbenutzung, zur Theorie, Geschichte, Kritik und Automatisierung der Lexikographie. Berlin/New York: Walter de Gruyter, 1998.

ZGUSTA, L. Manual of Lexicography. Prague/Paris: Academia/Mouton, 1971.

ZMiVLI. ZINGARELLI, N. A. Lo Zingarelli Minore. Vocabolario della lingua italiana. Bologna: Zanichelli, 2007.

\section{(c) (1) $\circledast \odot$}

Recebido em 15/12/2019. Aceito em 21/05/2020. 